\title{
What do Australian patients with inflammatory arthritis value in treatment? A discrete choice experiment
}

\author{
Kerrie-Anne Ho ${ }^{1,2}$ (D) Mustafa Acar $^{3}$ (D) $\cdot$ Andrea Puig $^{3}$ (D) Gabor Hutas $^{3} \cdot$ Simon Fifer $^{1}$ (D)
}

Received: 2 July 2019 / Revised: 9 October 2019 / Accepted: 4 November 2019 / Published online: 19 December 2019

(C) The Author(s) 2019

\begin{abstract}
Background and objectives The purpose of this study was to develop an understanding of treatment preferences in patients with inflammatory arthritis (IA) [rheumatoid arthritis (RA), ankylosing spondylitis (AS) and psoriatic arthritis (PsA)] focussing on treatment attributes that patients' value, their relative importance, and the risk-benefit trade-offs that characterise patients' choices around treatment.

Methods A discrete choice experiment (DCE) approach was used. Attributes of interest were clinical efficacy; slowing of disease progression; risk of mild-moderate side effects; risk of severe side effects; frequency of administration; real-world product evidence; management of related conditions; and availability of a patient support programme. Using data from the DCE component, a restricted latent class model (LCM) was estimated to determine discrete 'classes' of treatment preferences.

Results In this analysis, 206 participants were included (AS $n=59$; PsA $n=62 ;$ RA $n=85$ ). Two classes were identified. For 'class 1' (59.9\%), the most important attributes (across all treatment modalities) were preventing disease progression, clinical efficacy and risk of mild-to-moderate side effects. For 'class 2' (40.1\%), clinical and non-clinical attributes were important, and attribute importance depended on treatment modality. Patient demographic and treatment characteristics did not predict class membership.

Conclusion For most patients with IA, clinical efficacy, stopping disease progression and risks of mild-to-moderate side effects are important treatment attributes. Patients with prior biologic DMARD experience had greater preference for injection treatments. For a subset of patients, patient support programmes and the frequency of administration were important. Clinicians should be mindful of preferences when prescribing treatment to patients with IA.

Key Points

- Most patients consider clinical efficacy, stopping disease progression and the risk of mild-to-moderate side effects as important treatment attributes

- Patients with prior biologic DMARD experience have greater preference for injection treatments.

- For a subset of patients, patient support programmes, and the frequency of administration were important.

- Clinicians should be mindful of preferences when prescribing treatment to patients with IA.
\end{abstract}

Keywords Inflammatory arthritis $\cdot$ Patient preference $\cdot$ Treatment attributes

Electronic supplementary material The online version of this article (https://doi.org/10.1007/s10067-019-04843-4) contains supplementary material, which is available to authorized users.

\section{Simon Fifer}

simon.fifer@cappre.com.au

1 Community and Patient Preference Research Pty Ltd, Sydney, NSW, Australia

2 Present address: Evidera, London, UK

3 Outcomes Research, Janssen-Cilag Pty Ltd, North Ryde, NSW, Australia

\section{Introduction}

Patients with inflammatory auto-immune diseases such as rheumatoid arthritis (RA), ankylosing spondylitis (AS) and psoriatic arthritis (PsA) commonly experience chronic pain that negatively impacts their quality of life and functional capacity. Initially patients will be prescribed simple analgesics, such as non-steroidal anti-inflammatory drugs (NSAIDs) that can reduce symptoms of disease such as pain and inflammation [1]. Most patients progress to treatment with disease-modifying antirheumatic drugs (DMARDs) which 
can delay the progression of their disease [1]. DMARDs are divided into conventional synthetic DMARDS (csDMARDs) biologic DMARDs (bDMARDs) and targeted synthetic DMARDs (tsDMARDs). Patients typically commence treatment on csDMARDs (with the exception of those where the inflammation is restricted to the spine, where csDMARDs are ineffective). If an adequate response is not obtained, treatments may be augmented or replaced with bDMARDs or tsDMARDs. The bDMARDs and tsDMARDs are associated with improved clinical outcomes, quality of life and functioning in patients with inflammatory arthritis [2-4].

While clinical trials for treatments used in inflammatory arthritis provide useful safety and efficacy evidence, other factors such as burden of disease, impact of treatment on quality of life, and convenience of treatment are often overlooked. From a patient-centricity perspective, these factors are important to consider and may aid in shared decision-making between patients and physicians. Understanding patients' preferences for the attributes and trade-offs they are willing to accept in respect to arthritis treatment will assist in more informed decisions for future treatment options. In addition, there is evidence to suggest that patient preference and medication beliefs are associated with adherence and treatment persistence [5]. Given that adherence and treatment persistence are an important determinant of treatment outcomes, it is especially important that patient preferences are taken into account.

One method to assess patient preferences is to use a discrete choice experiment approach. DCE were first developed early last century to compare two alternatives. Since then, they have been extended through theory and modelling and are frequently used to understand preferences [6-8]. DCE are commonly used in experiments assessing patient preferences for different treatments and have been used in several therapeutic areas including arthritis [5, 9-15]. Using data from the DCE component, a restricted latent class model (LCM) can be estimated [16]. The LCM allows for preference heterogeneity, that is, different patients can have different marginal utilities or parameter weights for each of the features, which is implemented using discrete distributions. These discrete distributions are referred to as 'classes'. A LCM helped to identify potential causes of heterogeneity in treatment preferences and is considered better than traditional stratification based on observed characteristics [14]. LCM was first introduced into health studies in the mid-1990s but has been more commonly used since 2010 [14]. The class assignment model is performed simultaneously with the traditional model to identify subsets of participants with homogeneous preferences within groups and heterogeneous preferences between groups [14]. As such, preference groups (or 'classes') may be distinguished by observable characteristics such as age, sex and diagnosis or might be 'latent' (or unobservable) such as perceptions, experience and beliefs [14].
Previous studies have been conducted to examine patient preferences in treatment choices, particularly in rheumatoid arthritis [5, 9-12]. For example, in one study, no difference in preference was reported between subcutaneous and oral treatments in the Argentinian context [10], but in Germany, patients preferred oral treatments [9]. Preference for oral treatments may be temporary, as those with experience with injections appear to have no preference for oral medication [17]. In Canada, there was heterogeneity in risk aversion [11], and in the USA, older patients preferred etanercept over other treatment options (including methotrexate, gold injections and leflunomide) due to aversion to drug toxicity [12]. Despite these differences, patients are willing to make trade-offs: in the USA, patients with RA were willing to pay an additional USD $\$ 30.00$ to use a bDMARD that has a safer short-term adverse event profile (compared to three csDMARDs with the same effectiveness) [12].

Patient preferences may differ depending on what jurisdiction the patient lives in because the healthcare systems differ in the costs and availability of treatments and due to cultural differences. In Australia, while the costs of DMARD treatments are subsidised by the government, availability of bDMARD and tsDMARD is restricted to patients who fail conventional therapy (csDMARDs for RA/PsA, or NSAIDs for AS). It is also important to consider that the patient preferences for different treatment attributes may differ from that of the rheumatologist, the pharmacist or the rheumatology nurse [15]. In Australia, the cost of all bDMARDs and tsDMARDs are similar; therefore the out-of-pocket cost for the both the government and the patient does not vary much by treatment. Therefore, in the Australian context, other attributes aside from efficacy and cost are important, such as patient preference, and these attributes may be important when assessing the effectiveness of treatments and may impact funding decisions in a constrained healthcare system.

To date, no studies have been performed in Australia that assess the patient preferences for the attributes associated with currently available treatments for inflammatory arthritis. The purpose of this study was to develop a greater understanding of treatment preferences in patients with inflammatory arthritis focussing on tsDMARDs and bDMARDs, the specific treatment attributes that patients value, their relative importance and the risk-benefit trade-offs that characterise patients' choices around treatment options.

\section{Methods}

This study received ethics approval through Bellberry Limited (2018-02-076), and informed consent was sought from all participants prior to participation. 


\section{Discrete choice experiments}

A discrete choice experiment involves a survey that asks questions about various treatment 'attributes'. This study used a discrete modelling approach to gain an understanding of the treatment preferences of patients with inflammatory arthritis. Attributes in this experiment are key characteristics of the medications, for example, efficacy or side effects. The respondent is asked to choose their preference between medications with different attributes to explore their treatment preferences. Attributes were developed using qualitative methods [18] that were guided by extensive searches of the prescribing information and of the pivotal clinical trials of the currently available DMARDs. This allowed our attributes to be important to patients and policymakers and to be capable of being traded [18]. Attributes and levels are listed in Table 1.

\section{Survey instrument development}

The survey instrument was developed based on qualitative interviews of patients with inflammatory arthritis (AS, PsA or RA), which examined patient preference and determined the treatment attributes that contributed to decision-making. In addition, the pivotal clinical studies and prescribing information for each relevant DMARD were examined for important efficacy and tolerability aspects which enabled us to build clinically meaningful ranges of efficacy and tolerability for the DCE. Fourteen patients were interviewed (RA $n=4, \operatorname{AS} n=5$, PsA $n=5$ ).

The survey instrument consisted of questions on patient demographics, treatment history, comorbidities, the DCE scenarios, quality of life (using the Arthritis Impact Measurement Scales 2; AIMS2-SF) and then needle fear (measured on a 1-10 scale with higher scores indicating greater fear). An introductory section explained the survey and its content and included an explanation of the task prior to the choice sets being presented. Sixty DCE scenarios were divided into 5 blocks of 12 discrete choice tasks in which patients were asked to choose their preferred treatment for each task. The attributes of interest were clinical efficacy; slowing of disease progression; risk of mildmoderate side effects; risk of severe side effects; frequency of administration; real-world product evidence ("tried and tested'); management of related conditions; and availability of a patient support programme (Table 2). A labelled experimental design was used, with treatment profiles labelled as 'oral', 'injection', 'infusion' and 'none' (as an opt-out). An example DCE task is shown in Fig. 1. The online survey was designed to take approximately $20 \mathrm{mi}-$ nutes to complete. Injection fear was measured on a 10 point scale from 1 'I don't mind them' to 10 'I avoid them at all costs'.

\section{Study sample}

Patients were recruited through consumer groups including Arthritis Australia, Psoriasis Australia and the Research Now SSI (RNSSI) online consumer panel. To be eligible for the study, patients had to be aged 18 years or over with a diagnosis of AS, PsA or RA. Patients were classified as being 'biologic or targeted synthetic DMARD-naïve', that is, had never received a bDMARD or tsDMARD for the treatment of arthritis; 'biologic or targeted synthetic DMARD-qualified', that is, patients who were not currently on a bDMARD/tsDMARD but met the Australian Pharmaceutical Benefits Scheme eligibility criteria for bDMARD/tsDMARD treatment; or 'biologic or targeted synthetic DMARD-experienced', that is, patients who were currently being treated with a bDMARD/tsDMARD for treatment of arthritis. Patients were excluded if they had been diagnosed with more than one form of inflammatory arthritis (because we wanted experiences/preferences to be attributed to a single condition), worked for a pharmaceutical company, did not have access to the Internet or could not read and understand English without the need of a translator. Control measures were also implemented to minimise survey completion by non-serious/dishonest respondents, such as excluding those who indicated that they had a fabricated disease and those who did not undergo relevant diagnostic procedures to attain their arthritis diagnosis. Prior to participation, patients read a participant information sheet and provided consent online. Patients were reimbursed AUD $\$ 25$ for their participation, which they could either keep or donate to Arthritis Australia. Data were collected between August and September 2018.

\section{Analysis}

Data were cleaned to remove participants who had incoherent open-text responses, who completed the survey in under 10 minutes or who opted out in all 12 of the DCE scenarios. Descriptive statistics were performed for each of the patient cohorts using SPSS v25 (IBM, NY, USA). The combinations of levels for each attribute in the DCE were designed using the techniques proposed by Rose and Bliemer [19]. A Bayesian D-efficient design with basic priors to account for the direction of each parameter was used to structure the DCE. This was implemented in Ngene v1.1.2 (ChoiceMetrics, NSW, Australia), a software tool used to generate stated choice experimental design. Use of a Bayesian D-efficient design allowed us to estimate suitable models with smaller sample sizes. Models were estimated using Nlogit 6.0 (Econometric Software Inc., NY, USA). The adjusted McFadden Pseudo R-squared was used to assess model fit. Further information can be found in the Supplemental Text. 
Table 1 Characteristics and levels for the DCE

\begin{tabular}{|c|c|c|c|}
\hline Characteristics & Oral (home) & Subcutaneous injection (home) & Infusion (hospital/clinic) \\
\hline \multirow[t]{3}{*}{ Clinical Efficacy } & $20 \%$ improvement in pain and mobility & $20 \%$ improvement in pain and mobility & $20 \%$ improvement in pain and mobility \\
\hline & $50 \%$ improvement in pain and mobility & $50 \%$ improvement in pain and mobility & $50 \%$ improvement in pain and mobility \\
\hline & $70 \%$ improvement in pain and mobility & $70 \%$ improvement in pain and mobility & $70 \%$ improvement in pain and mobility \\
\hline \multirow{3}{*}{$\begin{array}{l}\text { Slows the progress } \\
\text { of the disease }\end{array}$} & Does not slow disease progression & Does not slow disease progression & Does not slow disease progression \\
\hline & Slows disease progression & Slows disease progression & Slows disease progression \\
\hline & Stops disease progression & Stops disease progression & Stops disease progression \\
\hline \multirow{4}{*}{$\begin{array}{l}\text { Mild-moderate } \\
\text { side effects }\end{array}$} & $5 \%$ chance & $0 \%$ chance & $0 \%$ chance \\
\hline & $20 \%$ chance & $15 \%$ chance & $10 \%$ chance \\
\hline & $35 \%$ chance & $30 \%$ chance & $20 \%$ chance \\
\hline & $50 \%$ chance & $45 \%$ chance & $30 \%$ chance \\
\hline \multirow[t]{2}{*}{ Severe side effects } & $<1 \%$ chance & $<1 \%$ chance & $<1 \%$ chance \\
\hline & 1 to $5 \%$ chance & 1 to $5 \%$ chance & 1 to $5 \%$ chance \\
\hline \multirow{4}{*}{$\begin{array}{l}\text { Frequency of } \\
\text { taking treatment }\end{array}$} & Twice a day & Once a week & Once every 4 weeks \\
\hline & Once a day & Once every 2 weeks & Once every $6-8$ weeks \\
\hline & Once a week & Once every 4 weeks & Once every 6 months (RA only) \\
\hline & & Once every 12 weeks (PSA only) & \\
\hline \multirow[t]{3}{*}{ Tried and tested } & Treatment available for less than 3 years & Treatment available for less than 3 years & Treatment available for less than 3 years \\
\hline & Treatment available for 3-7 years & Treatment available for $3-7$ years & Treatment available for 3-7 years \\
\hline & Treatment available for 7 years or more & Treatment available for 7 years or more & Treatment available for 7 years or more \\
\hline \multirow{3}{*}{$\begin{array}{l}\text { Management of } \\
\text { related } \\
\text { conditions }\end{array}$} & $\begin{array}{l}\text { Treatment approved only in arthritis } \\
\text { related conditions }\end{array}$ & $\begin{array}{l}\text { Treatment approved only in arthritis } \\
\text { related conditions }\end{array}$ & $\begin{array}{l}\text { Treatment approved only in arthritis } \\
\text { related conditions }\end{array}$ \\
\hline & $\begin{array}{l}\text { Treatment approved to manage other } \\
\text { auto-immune conditions (e.g. Crohn's } \\
\text { disease, psoriasis, uveitis, ulcerative } \\
\text { colitis, etc.) }\end{array}$ & $\begin{array}{l}\text { Treatment approved to manage other } \\
\text { auto-immune conditions (e.g. Crohn's } \\
\text { Disease, psoriasis, uveitis, ulcerative } \\
\text { colitis, etc.) }\end{array}$ & $\begin{array}{l}\text { Treatment approved to manage other } \\
\text { auto-immune conditions (e.g. Crohn's } \\
\text { disease, psoriasis, uveitis, ulcerative } \\
\text { colitis, etc.) }\end{array}$ \\
\hline & & & $\begin{array}{l}\text { Treatment approved in other auto-immune } \\
\text { conditions (e.g. Crohn's disease, } \\
\text { psoriasis, uveitis, ulcerative colitis, etc.) } \\
\text { and some cancers (rituximab only) }\end{array}$ \\
\hline \multirow{3}{*}{$\begin{array}{l}\text { Patient support } \\
\text { programme }\end{array}$} & No support service & No support service & No support service \\
\hline & $\begin{array}{l}\text { Nurse support phone line at no additional } \\
\text { cost }\end{array}$ & $\begin{array}{l}\text { Self-injection training and nurse support } \\
\text { phone line at no additional cost }\end{array}$ & $\begin{array}{l}\text { Appointment reminder service and nurse } \\
\text { support phone line at no additional cost }\end{array}$ \\
\hline & $\begin{array}{l}\text { Nurses support phone line and additional } \\
\text { services around self-management (e.g. } \\
\text { pathology advice/services, dietary and } \\
\text { exercise advice, health-tracking tech- } \\
\text { nology [e.g. Fitbit]) }\end{array}$ & $\begin{array}{l}\text { Self-injection training, nurse support } \\
\text { phone line and additional services } \\
\text { around self-management (e.g., patholo- } \\
\text { gy advice/services, dietary and exercise } \\
\text { advice, health-tracking technology [e.g. } \\
\text { Fitbit]) }\end{array}$ & $\begin{array}{l}\text { Appointment reminder service, nurse } \\
\text { support phone line and additional } \\
\text { services around self-management (e.g. } \\
\text { pathology advice/services, dietary and } \\
\text { exercise advice, health-tracking tech- } \\
\text { nology [e.g. Fitbit]) }\end{array}$ \\
\hline
\end{tabular}

A decision support system (DSS) or dashboard was created using the model parameters. The DSS can be manipulated to provide estimates of predicted treatment uptake based on the treatment attributes examined in the DCE (the DSS can be accessed via https://cappre.shinyapps.io/Arthritis/). This can assist stakeholders in interpretation of the model and allows them to make comparisons between treatments with different treatment characteristics. Using this, we estimated patient preference for the different arthritis treatments available and the relative importance of treatment attributes on preferences for treatment. Results are presented as mean \pm standard deviation, unless otherwise indicated.

\section{Results}

Of the 245 participants who completed survey, 206 were included in the analysis (AS $n=59$; PsA $n=62$; RA $n=85$ ). The demographics of patients included in the DCE are reported in Table 2 . The majority of participants were female $(71 \%)$, aged in their 40 s or over (74\%) and living in a metropolitan area (57\%).

\section{bDMARD experience and injection fear}

One third of patients had bDMARD/tsDMARD experience (33\%), with a smaller proportion eligible for bDMARD/ 


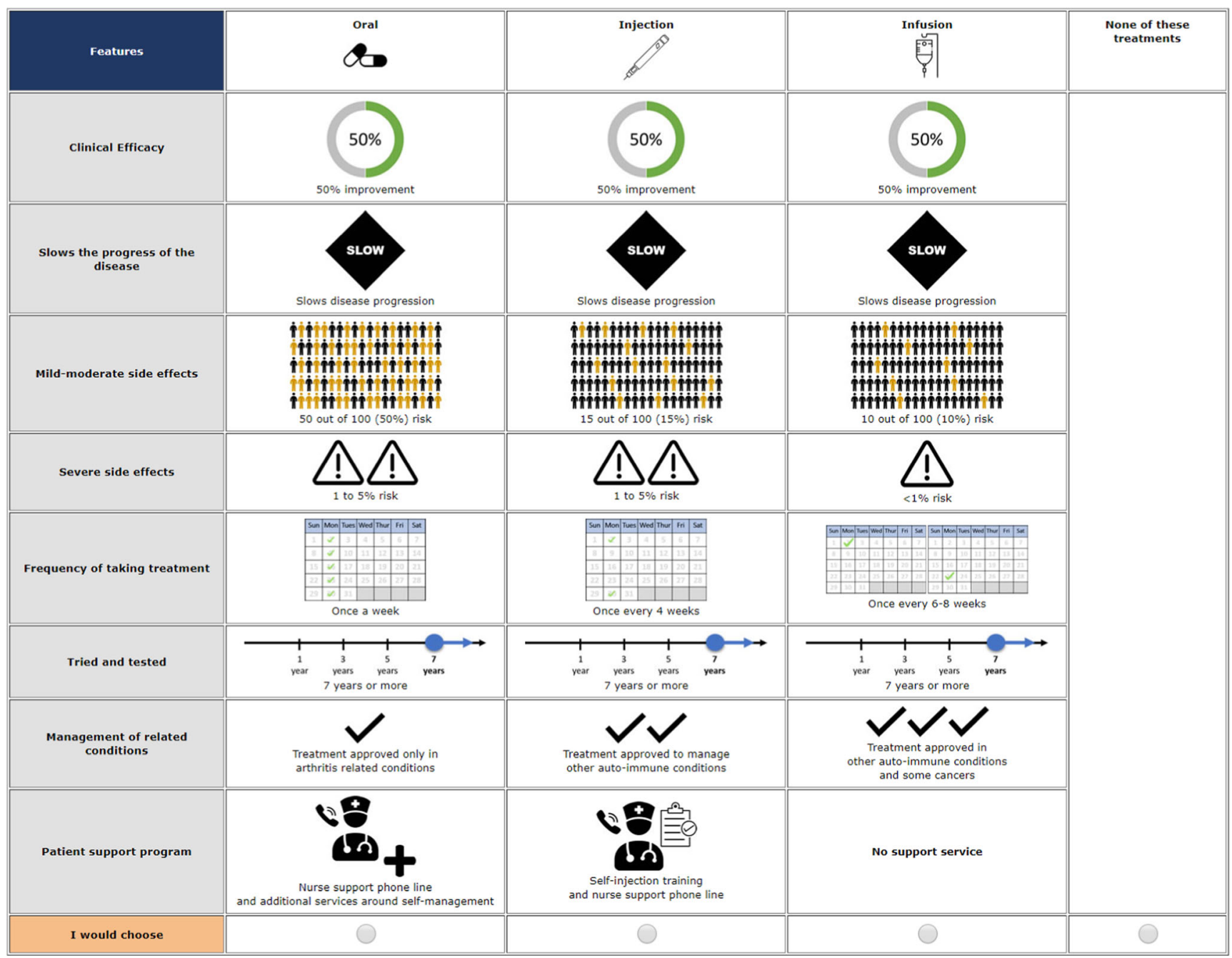

Fig. 1 Example discrete choice experiment question

tsDMARD therapy who had not ever used these treatments (16\%). Just over half of patients had never used a bMDARD/ tsDMARD (52\%). Overall, injection fear was reported on a 110 scale as $3.47 \pm 2.89$. Injection fear was lower in patients who had previous experience of bDMARDs or self-injection experience ( $2.52 \pm 2.45$ and $2.40 \pm 2.00$, respectively), compared to those who had no experience with self-injections $(3.64 \pm 2.84)$. The greatest injection fear was held by the small number of patients who had bDMARD/tsDMARD experience but had no injection experience $(3.86 \pm 3.24)$. Given the treatments available to patients in Australia at the time of data collection, these patients were likely prescribed the tsDMARD tofacitinib. Of those with self-injection experience, just under half were never fearful of injections and are still not $(49.0 \%)$, a third were fearful but are no longer (34.4\%), and smaller proportions were and still are fearful of injections $(11.5 \%)$ or other $(5.2 \%)$. The 'other' included those who were still hesitant but were no longer fearful or those who looked forward to the injection as it gave them a sense of control.

\section{Results of the DCE}

The DCE model output is presented in Table 3 . The best fitting model was a restricted latent class model with some parameters that were non-significant in preliminary models restricted to zero. Using AIC and BIC as a criteria, the appropriate number of classes in our model was two. The classes were differentiated by the relative importance of clinical and nonclinical attributes, experience with bDMARD/tsDMARD and treatment modality preferences. Patient demographic and treatment characteristics did not predict class membership.

For 'class 1', clinical attributes that were significant across all treatment modalities were preventing disease progression, clinical efficacy, and the risk of mild to moderate side effects. Infusion frequency was important for patients with RA. Compared to patients who were bDMARD-naïve, bDMARD-experienced patients were more likely to prefer injection and infusion treatments), all else being equal. All patients (RA, AS, PsA) preferred oral treatment over no treatment (see also Section 4.3). 
Table 2 Participant demographics

$\begin{array}{llll}\text { RA } & \text { AS } & \text { PsA } & \text { Total } \\ \mathrm{N}=85 & \mathrm{~N}=59 & \mathrm{~N}=62 & \mathrm{~N}=206\end{array}$

\begin{tabular}{|c|c|c|c|c|c|c|c|c|}
\hline \multicolumn{9}{|l|}{ Sex, n (\%) } \\
\hline Male & 25 & $29.41 \%$ & 16 & $27.12 \%$ & 18 & $29.03 \%$ & 59 & $28.64 \%$ \\
\hline Female & 59 & $69.41 \%$ & 43 & $72.88 \%$ & 44 & $70.97 \%$ & 146 & $70.87 \%$ \\
\hline Prefer not to answer & 1 & $1.18 \%$ & 0 & $0.00 \%$ & 0 & $0.00 \%$ & 1 & $0.49 \%$ \\
\hline \multicolumn{9}{|l|}{ Age (years), n (\%) } \\
\hline$\leq 40$ & 17 & $20.00 \%$ & 20 & $33.90 \%$ & 17 & $27.42 \%$ & 54 & $26.21 \%$ \\
\hline $41-60$ & 32 & $37.65 \%$ & 22 & $37.29 \%$ & 33 & $53.23 \%$ & 87 & $42.23 \%$ \\
\hline$>60$ & 36 & $42.35 \%$ & 17 & $28.81 \%$ & 12 & $19.35 \%$ & 65 & $31.55 \%$ \\
\hline \multicolumn{9}{|l|}{ Occupation status, n (\%) } \\
\hline Working (full-time) & 24 & $28.24 \%$ & 20 & $33.90 \%$ & 19 & $30.65 \%$ & 63 & $30.58 \%$ \\
\hline Working (part-time) & 17 & $20.00 \%$ & 15 & $25.42 \%$ & 8 & $12.90 \%$ & 40 & $19.42 \%$ \\
\hline Working (casual) & 9 & $10.59 \%$ & 2 & $3.39 \%$ & 6 & $9.68 \%$ & 17 & $8.25 \%$ \\
\hline Not working & 4 & $4.71 \%$ & 5 & $8.47 \%$ & 10 & $16.13 \%$ & 19 & $9.22 \%$ \\
\hline Home duties/caring responsibilities & 4 & $4.71 \%$ & 1 & $1.69 \%$ & 6 & $9.68 \%$ & 11 & $5.34 \%$ \\
\hline Retired & 24 & $28.24 \%$ & 14 & $23.73 \%$ & 10 & $16.13 \%$ & 48 & $23.30 \%$ \\
\hline Student & 1 & $1.18 \%$ & 1 & $1.69 \%$ & 2 & $3.23 \%$ & 4 & $1.94 \%$ \\
\hline Other (including DSP) & 2 & $2.35 \%$ & 1 & $1.69 \%$ & 1 & $1.61 \%$ & 4 & $1.94 \%$ \\
\hline \multicolumn{9}{|l|}{ Household composition, $\mathrm{n}(\%)$} \\
\hline Couple with no children & 24 & $28.24 \%$ & 15 & $25.42 \%$ & 16 & $25.81 \%$ & 55 & $26.70 \%$ \\
\hline Couple family with children & 25 & $29.41 \%$ & 23 & $38.98 \%$ & 28 & $45.16 \%$ & 76 & $36.89 \%$ \\
\hline One parent family & 8 & $9.41 \%$ & 1 & $1.69 \%$ & 6 & $9.68 \%$ & 15 & $7.28 \%$ \\
\hline Single person household & 20 & $23.53 \%$ & 18 & $30.51 \%$ & 9 & $14.52 \%$ & 47 & $22.82 \%$ \\
\hline Group household (i.e. shared) & 7 & $8.24 \%$ & 2 & $3.39 \%$ & 3 & $4.84 \%$ & 12 & $5.83 \%$ \\
\hline Prefer not to answer & 1 & $1.18 \%$ & 0 & $0.00 \%$ & 0 & $0.00 \%$ & 1 & $0.49 \%$ \\
\hline \multicolumn{9}{|l|}{ Area, n (\%) } \\
\hline Metro/city & 54 & $63.53 \%$ & 30 & $50.85 \%$ & 33 & $53.23 \%$ & 117 & $56.80 \%$ \\
\hline Regional & 24 & $28.24 \%$ & 23 & $38.98 \%$ & 18 & $29.03 \%$ & 65 & $31.55 \%$ \\
\hline Rural & 7 & $8.24 \%$ & 6 & $10.17 \%$ & 11 & $17.74 \%$ & 24 & $11.65 \%$ \\
\hline \multicolumn{9}{|l|}{ Household annual income, $\mathrm{n}(\%)$} \\
\hline Up to $\$ 29,999$ & 21 & $24.71 \%$ & 8 & $13.56 \%$ & 8 & $12.90 \%$ & 37 & $17.96 \%$ \\
\hline$\$ 30,000$ to $\$ 59,999$ & 19 & $22.35 \%$ & 9 & $15.25 \%$ & 13 & $20.97 \%$ & 41 & $19.90 \%$ \\
\hline$\$ 60,000$ to $\$ 89,999$ & 11 & $12.94 \%$ & 9 & $15.25 \%$ & 7 & $11.29 \%$ & 27 & $13.11 \%$ \\
\hline$\$ 90,000$ to $\$ 119,999$ & 10 & $11.76 \%$ & 14 & $23.73 \%$ & 9 & $14.52 \%$ & 33 & $16.02 \%$ \\
\hline$\geq \$ 120,000$ & 15 & $17.65 \%$ & 15 & $25.42 \%$ & 16 & $25.81 \%$ & 46 & $22.33 \%$ \\
\hline Prefer not to answer & 9 & $10.59 \%$ & 4 & $6.78 \%$ & 9 & $14.52 \%$ & 22 & $10.68 \%$ \\
\hline \multicolumn{9}{|l|}{ Highest level of education, $\mathrm{n}(\%)$} \\
\hline Year 11 or below & 15 & $17.65 \%$ & 12 & $20.34 \%$ & 12 & $19.35 \%$ & 39 & $18.93 \%$ \\
\hline Year 12 & 10 & $11.76 \%$ & 7 & $11.86 \%$ & 6 & $9.68 \%$ & 23 & $11.17 \%$ \\
\hline Certificate III/IV & 18 & $21.18 \%$ & 14 & $23.73 \%$ & 11 & $17.74 \%$ & 43 & $20.87 \%$ \\
\hline$>$ Bachelor degree & 41 & $48.24 \%$ & 26 & $44.07 \%$ & 33 & $53.23 \%$ & 100 & $48.54 \%$ \\
\hline Prefer not to answer & 1 & $1.18 \%$ & 0 & $0.00 \%$ & 0 & $0.00 \%$ & 1 & $0.49 \%$ \\
\hline Time since diagnosis, years, mean (SD) & 8.3 & $(6.6)$ & 8.8 & (7.3) & 8.8 & $(6.6)$ & 8.6 & $(6.8)$ \\
\hline \multicolumn{9}{|l|}{ Treatment experience, $\mathrm{n}(\%)$} \\
\hline bDMARD-experienced & 24 & $28.24 \%$ & 24 & $40.68 \%$ & 19 & $30.65 \%$ & 67 & $32.52 \%$ \\
\hline bDMARD-qualified & 9 & $10.59 \%$ & 3 & $5.08 \%$ & 20 & $32.26 \%$ & 32 & $15.53 \%$ \\
\hline bDMARD-naïve on opioids only & 13 & $15.29 \%$ & 11 & $18.64 \%$ & 6 & $9.68 \%$ & 30 & $14.56 \%$ \\
\hline bDMARD-naïve on other treatments (not opioids) & 39 & $45.88 \%$ & 21 & $35.59 \%$ & 17 & $27.42 \%$ & 77 & $37.38 \%$ \\
\hline
\end{tabular}


Table 2 (continued)

\begin{tabular}{|c|c|c|c|c|c|c|c|c|}
\hline \multirow[b]{2}{*}{ Non-steroidal anti-inflammatory drugs (NSAIDs) } & \multicolumn{2}{|c|}{$\begin{array}{l}\mathrm{RA} \\
\mathrm{N}=85\end{array}$} & \multicolumn{2}{|c|}{$\begin{array}{l}\text { AS } \\
\mathrm{N}=59\end{array}$} & \multicolumn{2}{|c|}{$\begin{array}{l}\text { PsA } \\
\mathrm{N}=62\end{array}$} & \multicolumn{2}{|c|}{$\begin{array}{l}\text { Total } \\
N=206\end{array}$} \\
\hline & 46 & $54.80 \%$ & 31 & $52.50 \%$ & 34 & $54.80 \%$ & 111 & $54.10 \%$ \\
\hline Steroids & 19 & $22.60 \%$ & 4 & $6.80 \%$ & 10 & $16.10 \%$ & 33 & $16.10 \%$ \\
\hline Methotrexate & 25 & $29.80 \%$ & 5 & $8.50 \%$ & 25 & $40.30 \%$ & 55 & $26.80 \%$ \\
\hline Biologic drugs & 17 & $20.20 \%$ & 21 & $35.60 \%$ & 16 & $25.80 \%$ & 54 & $26.30 \%$ \\
\hline Hydroxychloroquine & 17 & $20.20 \%$ & 1 & $1.70 \%$ & 3 & $4.80 \%$ & 21 & $10.20 \%$ \\
\hline Leflunomide & 8 & $9.50 \%$ & 0 & $0.00 \%$ & 13 & $21.00 \%$ & 21 & $10.20 \%$ \\
\hline Sulfasalazine & 9 & $10.70 \%$ & 3 & $5.10 \%$ & 5 & $8.10 \%$ & 17 & $8.30 \%$ \\
\hline Opioid pain medications & 23 & $27.40 \%$ & 20 & $33.90 \%$ & 15 & $24.20 \%$ & 58 & $28.30 \%$ \\
\hline Others & 0 & $0.00 \%$ & 1 & $1.70 \%$ & 0 & $0.00 \%$ & 1 & $0.50 \%$ \\
\hline Not currently taking medications & 12 & $14.30 \%$ & 12 & $20.30 \%$ & 8 & $12.90 \%$ & 32 & $15.60 \%$ \\
\hline \multicolumn{9}{|l|}{ Length of time on current medications, $\mathrm{n}(\%)$} \\
\hline Less than 1 month & 4 & $5.63 \%$ & 3 & $6.52 \%$ & 3 & $5.56 \%$ & 10 & $5.85 \%$ \\
\hline $1-3$ months & 2 & $2.82 \%$ & 1 & $2.17 \%$ & 4 & $7.41 \%$ & 7 & $4.09 \%$ \\
\hline $3-6$ months & 6 & $8.45 \%$ & 4 & $8.70 \%$ & 3 & $5.56 \%$ & 13 & $7.60 \%$ \\
\hline 6 months or more & 59 & $83.10 \%$ & 38 & $82.61 \%$ & 44 & $81.48 \%$ & 141 & $82.46 \%$ \\
\hline \multicolumn{9}{|l|}{ AIMS2 score, mean (SD) } \\
\hline Standardised physical score & 2.74 & $(1.84)$ & 2.36 & $(1.57)$ & 2.76 & $(1.77)$ & 2.64 & $(1.75)$ \\
\hline Standardised symptoms score & 4.74 & $(2.61)$ & 5.9 & $(2.8)$ & 5.46 & $(2.96)$ & 5.29 & $(2.8)$ \\
\hline Standardised affect score & 4.02 & $(2.49)$ & 4.21 & $(2.29)$ & 4.49 & $(2.42)$ & 4.22 & $(2.41)$ \\
\hline Standardised social interaction score & 6.04 & $(2.14)$ & 6.48 & $(1.92)$ & 6.36 & $(1.63)$ & 6.27 & $(1.94)$ \\
\hline Standardised role score & 2.43 & $(2.51)$ & 2.68 & $(2.7)$ & 2.9 & $(2.88)$ & 2.65 & $(2.68)$ \\
\hline
\end{tabular}

*multiple response item, percentages do not sum to $100 \%$

For 'class 2', there were clinical as well as non-clinical attributes that were significant depending on the treatment modality. For all patients in this class, attributes that were significant included preventing disease progression, clinical efficacy and the availability of patient support programmes. Injection treatments that were less frequent were also a significant factor for patients. Similar to "class 1', compared to patients who were bDMARD-naïve, bDMARD-experienced patients were more likely to prefer injection treatments, all else being equal. Further, compared to patients who were bDMARD/tsDMARD-naïve, bDMARD/tsDMARD-experienced patients were less likely to prefer oral treatments), all else being equal. All else being equal patients in class 2 with AS preferred no treatment over oral treatment, whereas patients with PsA or RA preferred oral treatment over injection and infusion treatments (see also Supplemental text)

\section{Attribute importance}

In this model, the parameter estimates cannot be directly compared as they were on different scales (e.g. clinical efficacy was measured as a continuous variable with percentage levels, and disease progression was measured as a categorical variable with a base as reference). The DSS (Fig. 2) was used to calculate relative attribute importance by changing from the lowest attribute level to the highest attribute level (utility) and recording the change in probabilities. These values were then compared and used to calculate the overall percentage weight that attribute contributes to changes in utility (i.e. relative attribute importance). When comparing attribute importance, it is important to note that the values were based on the levels chosen in the experiment and should be viewed in this context.

The strength of attribute importance differed by class, treatment modality and diagnosis (see Fig. 3). For example, in patients with RA in class 1 , the relative attribute importance for oral therapies was disease progression $(39.3 \%)$, clinical efficacy $(36.0 \%)$ and risk of moderate side effects $(24.7 \%)$. For injections, the relative attribute importance was disease progression $(39.9 \%)$, clinical efficacy $(37.2 \%)$ and risk of moderate side effects $(23.0 \%)$. For infusions, the relative attribute importance was disease progression (38.5\%), clinical efficacy (34.6\%), frequency of administration (11.3\%), risk of moderate side effects $(11.4 \%)$ and real-world treatment evidence $(4.4 \%)$; see also Fig. 3. For patients with RA in class 2 , the relative attribute importance for oral therapies was clinical efficacy 
莺

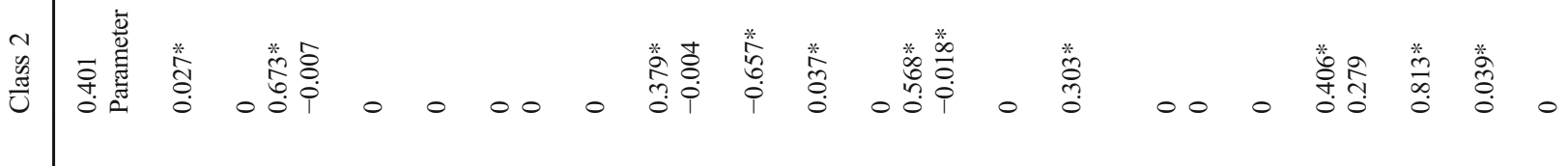

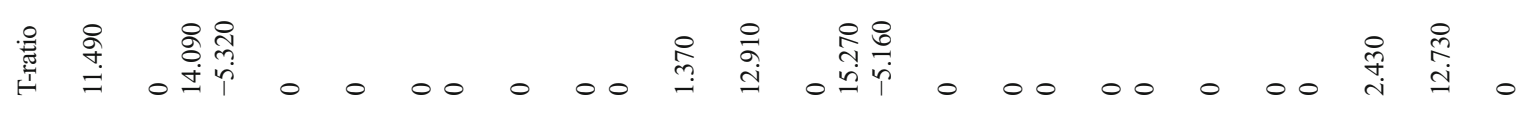

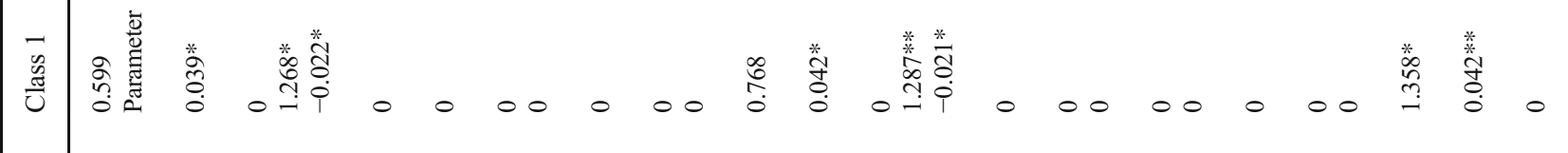

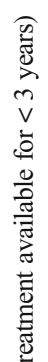

$\widehat{x}$
$\frac{1}{0}$
0
0

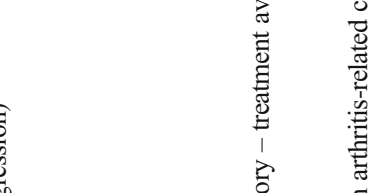

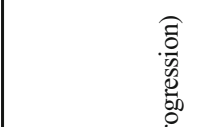<smiles>C1CCC1</smiles>

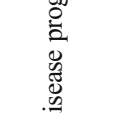

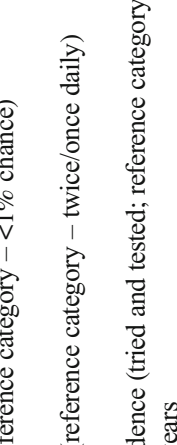

$\sqrt{2}$

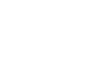




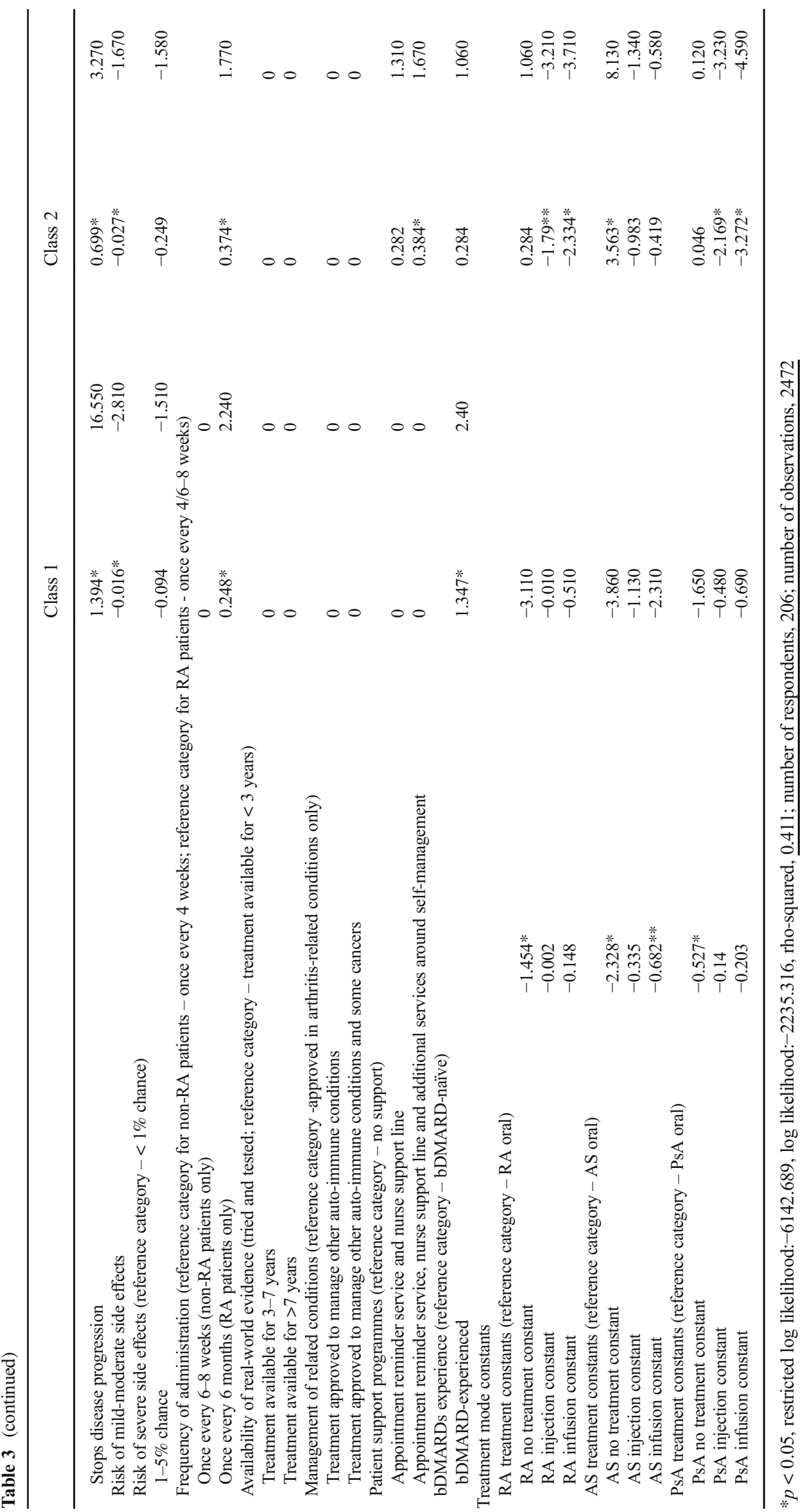




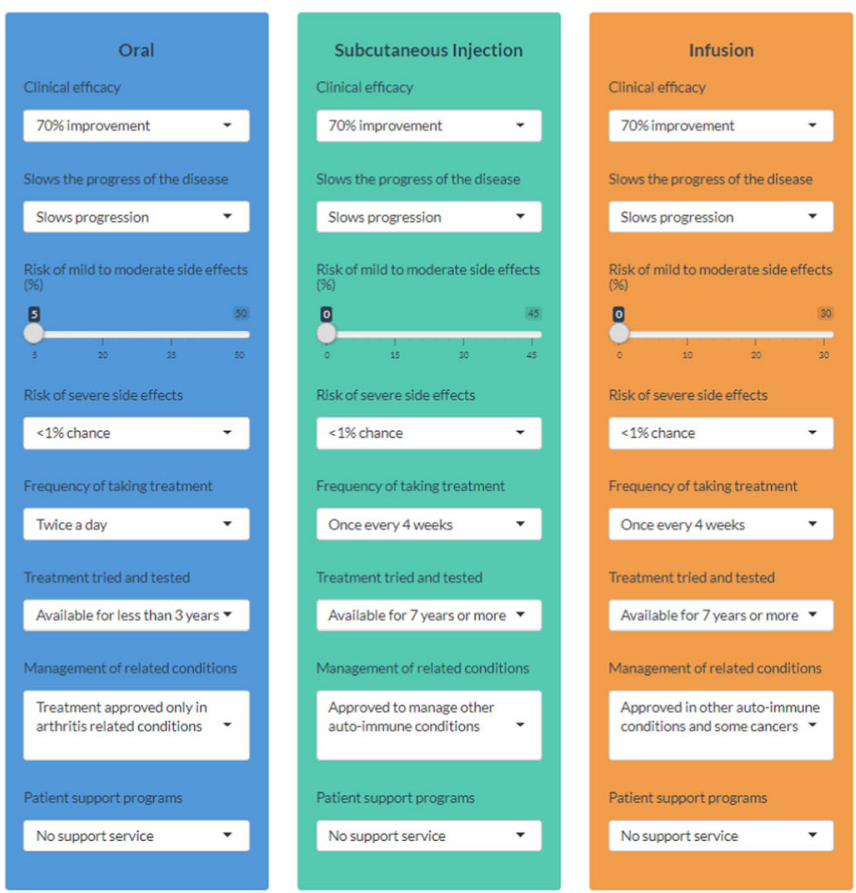

Fig. 2 Predicted treatment update decision support system example

(35.2\%), disease progression (34.9\%) and availability of patient support programmes $(21.3 \%)$. For injections, the relative attribute importance was disease progression (27.9\%), clinical efficacy $(21.3 \%)$ and availability of patient support programmes $(20.8 \%)$. For infusions, the relative attribute importance was disease progression (24.1\%), clinical efficacy (20.6\%) and availability of patient support programmes (17.3\%).

\section{Predicted treatment uptake}

The LCM output was inserted into a DSS which can be used to examine the predicted treatment uptake of any treatment that can be represented by the attributes and levels included in the DCE. The DSS was developed as an interactive web-based front end using Shiny (RStudio, Boston MA, USA). Changes or differences in predicted treatment uptake can be examined by manipulating the attribute levels in the DSS and observing the resulting preference shares. For example, in Fig. 2, the DSS was set to examine the predicted treatment uptake for a newer oral treatment (treatment available for less than 3 years) and an injection or infusion treatment (treatment available for 7 years or more) with similar clinical characteristics $(70 \%$ clinical efficacy, slows disease progression and minimal side effects). The predicted treatment uptake for bDMARD-naïve patients across the different types of inflammatory arthritis is presented. An interactive DSS demonstrating results can be found at https://cappre.shinyapps. io/Arthritis/.

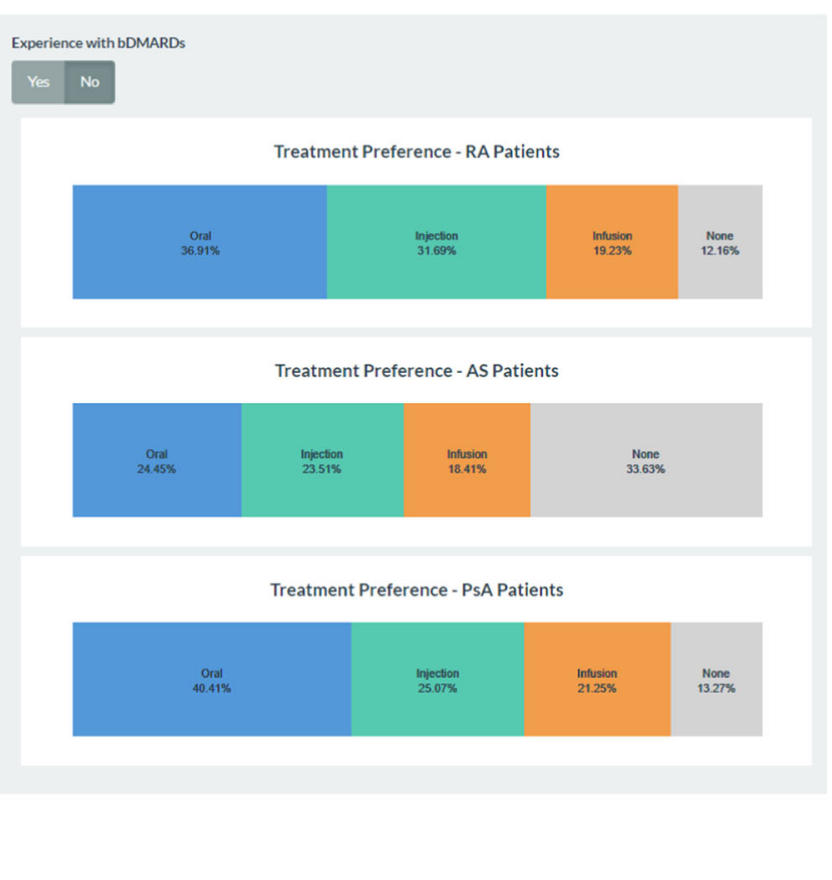

\section{Discussion}

Our study found that there were two discernible latent classes of patients with different patient profiles. For patients in class 1 , stopping disease progression was the most important attribute, while clinical efficacy was the most important in class 2 . Despite this, the top two attributes in both classes were stopping disease progression and clinical efficacy. Having previous experience with bDMARDs influenced preference for different treatment modalities within each class. For the patients in class 2 , treatment frequency and the availability of patient support programmes were also important. It is somewhat unsurprising that clinical efficacy rates very highly as an attribute when considering treatment preference. Others have reported that pain is the preferred area for symptom improvement in patients with rheumatoid arthritis [20].

Needle fear is an important consideration when making treatment decisions. As bDMARDs are commonly administered as injection-based treatments, experience with injection treatment may influence patient's perceptions and preferences for different modes of treatment. Needle fear was generally low and got lower with injection experience (even though a small proportion of patients remained fearful despite injection experience). This is consistent with self-injection experience and needle fear findings in the literature [17].

Patient support programmes, such as those available in Australia when prescribed some bDMARDs, are an attempt to increase the effectiveness of treatment strategies and are used in a variety of settings. However, the availability of contexts of these programmes vary, and to our knowledge, no 

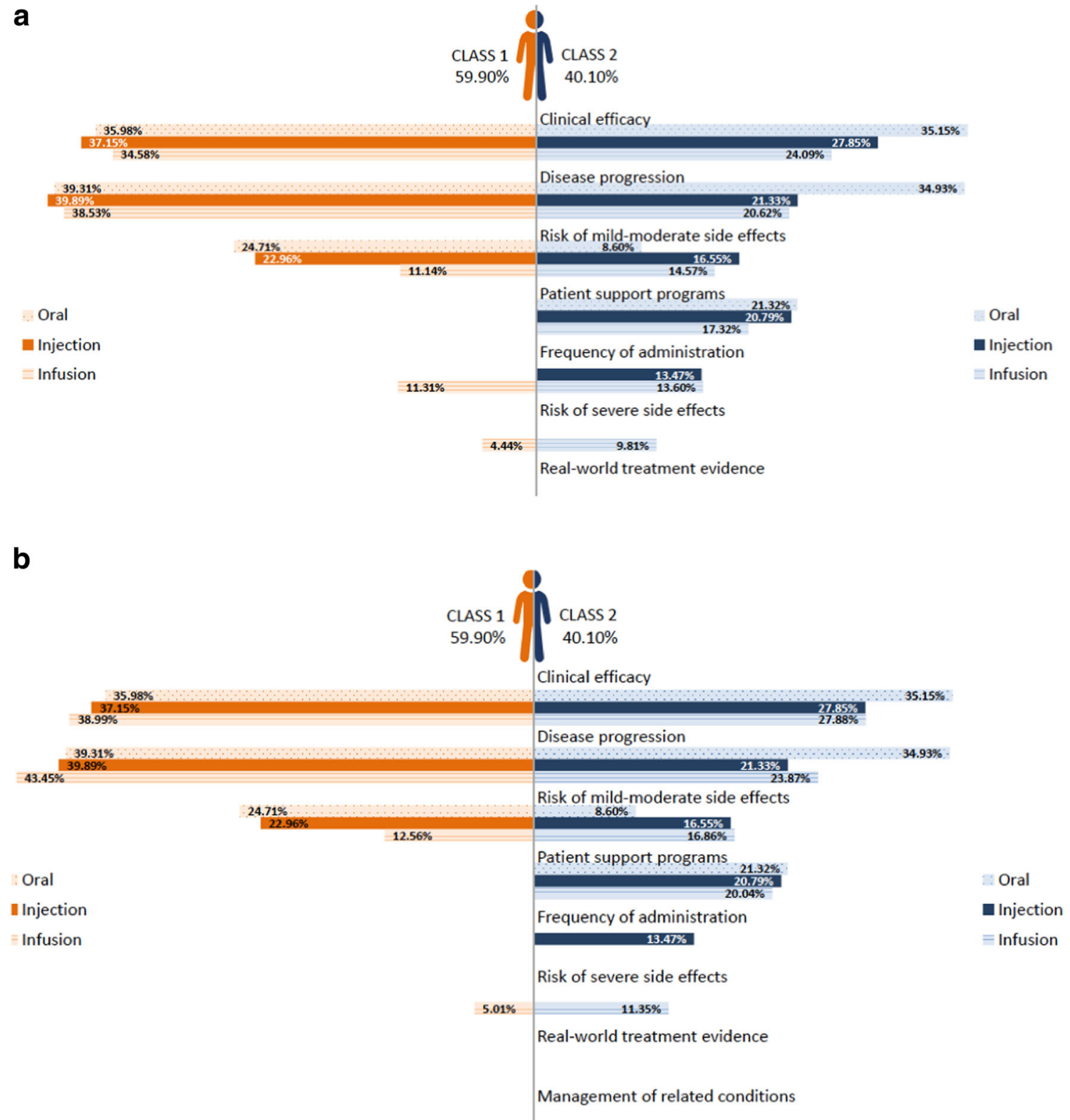

Fig. 3 Attribute importance by respondent class (A) RA patients and (B) PsA/AS patients

systematic evaluation of their effectiveness has been undertaken in the Australian setting. Given the patient preference for treatments with certain patient support programmes, this is an area that requires further research.

Taken together, our study has shown that there is a distribution of preferences, but that clinical efficacy, disease progression, availability of a patient support programme, side effects, needle fear and frequency of administration should be discussion points when talking to patients about their treatment options. Providing patients with input into their treatment choice and factoring in their preferences, such as through shared decision-making discussions with physicians, may improve both treatment adherence and treatment persistence. Treatment adherence is poor in arthritis, ranging from $47 \%$ to $89 \%$ [5]. Improved treatment adherence and persistence may lessen some of the longer-term morbidity associated with arthritis, perhaps allowing patients to work longer and provide a societal benefit. As such, it is important that economic evaluations, which typically focus only on the health outcomes of treatment, also focus on the benefits valued by patients and by society.

In the Australian context, currently available treatments have robust clinical programmes showing similar efficacy and ability to stop disease progression, which are clearly very important to all patients. Safety profiles, although not exactly the same, are comparable. Further, in the Australian setting, unlike in other countries, there are no differences in costs or eligibility for access. That is, the costs for the system and for the patients are the same. Furthermore, in Australia, a consulting 
rheumatologist can request a change in treatment for any reason to any one of the other government-subsidised bDMARD/ tsDMARDs as long as the patient had demonstrated a response to the prior treatment. So, in the Australian setting at least, the differences among the products are the mode of administration, dose, frequency, real-world experience and the local level of patient support. Among these, patient support is clearly important for a class of patients. Treatment frequency is also relevant for some. It is unclear, however, what support patients actually want. There are many options available currently to patients enrolled in patient support programmes including dietary advice, exercise advice, self-injection training, appointment reminders, etc. In this study, we did not separate out the health trackers from pathology, dietary or other advices. However, results suggest that for bDMARDs treatments, a subset of patients value the inclusion of self-injection training and the availability of a nurse support line as part of a patient support programme. Our findings highlight the value patients attribute to non-clinical characteristics of treatments and warrants additional research. Use of a patient support programme would allow valuable time within the specialist consultation to be spent on improving treatment outcomes.

Practically speaking, the DSS may be useful to rheumatologists who could input the characteristics of real treatments into the DSS to better understand the predicted treatment uptake on an aggregate level across different forms of inflammatory arthritis conditions. It will also allow rheumatologists to better understand the influence of prior bDMARD/tsDMARD experience on predicted treatment uptake.

This study has some limitations. For example, convenience sampling including patients who are involved in patient organisations and research registries was used. This may bias the results to patients who are more active in their selfmanagement and rheumatology care. Other than for the type of arthritis (RA, AS, PsA), quotas were not used to ensure representativeness of the sample to Australian patients. There is potential bias for patients who chose not to participate, which may reflect a group of patients that is actually indifferent about treatment choice. Further, patient experience with bMDARD/tsDMARD was not clearly differentiated. When the survey was conducted, tsDMARDs were only just made available to patients in Australia. It is possible that all relevant attributes were not tested in our model, for example, a recent Italian study has suggested that the manner, helpfulness, efficiency and courtesy of health personnel who assist a patient during treatment and related aspects might be important [15]. This attribute was not tested.

\section{Conclusions}

This study demonstrated that patients value treatment attributes differently. While a subgroup of patients only value clinical attributes, another subgroup of patients value both clinical and non-clinical attributes. Previous experience with bDMARDs/tsDMARDs may also influence patients' preferences for treatment modalities. These findings have important implications for shared decision-making in Australia where patients have access to different bDMARDs/tsDMARDs which are clinically similar but differ in the non-clinical treatment attributes (such as treatment frequency and availability of patient support groups).

Acknowledgements The authors thank Belinda Butcher BSc MBiostat Ph.D. CMPP AStat of WriteSource Medical Pty Ltd, Sydney, Australia, for providing medical writing support by preparing the manuscript outline, developing the first draft and collating and incorporating author comments. Medical writing support was funded by Jannsen-Cilag Pty Ltd in accordance with Good Publication Practice (GPP3) guidelines (http://www.ismpp.org/gpp3). The authors also thank Dr. Edward Wei and Ariana Cabrera for assistance with survey scripting and data management.

Funding information This study was funded by Janssen-Cilag Pty Ltd.

\section{Compliance with ethical standards}

Conflict of interest MA, AP and GH are employees of Janssen-Cilag, who manufacture golimumab (SIMPONI ${ }^{\circledR}$ ) and ustekinumab (STELARA®). KH and SF are employees of CaPPRe who were contracted by Janssen-Cilag to perform the experiments, provide data management and conduct the analysis.

Open Access This article is licensed under a Creative Commons Attribution 4.0 International License, which permits use, sharing, adaptation, distribution and reproduction in any medium or format, as long as you give appropriate credit to the original author(s) and the source, provide a link to the Creative Commons licence, and indicate if changes were made. The images or other third party material in this article are included in the article's Creative Commons licence, unless indicated otherwise in a credit line to the material. If material is not included in the article's Creative Commons licence and your intended use is not permitted by statutory regulation or exceeds the permitted use, you will need to obtain permission directly from the copyright holder. To view a copy of this licence, visit http://creativecommons.org/licenses/by/4.0/.

\section{References}

1. The Royal Australian College of General Practitioners (2009) Recommendations for the diagnosis and management of early rheumatoid arthritis. South Melbourne, VIC

2. Borse RH, Brown C, Muszbek N, Chaudhary MA, Kachroo S (2017) Cost-Effectiveness of golimumab in ankylosing spondylitis from the UK Payer Perspective. Rheumatol Ther 4(2):427-443. https://doi.org/10.1007/s40744-017-0083-1

3. Hoving JL, Bartelds GM, Sluiter JK, Sadiraj K, Groot I, Lems WF, Dijkmans BAC, Wijbrandts CA, Tak PP, Nurmohamed MT, Voskuyl AE, Frings-Dresen MHW (2009) Perceived work ability, quality of life, and fatigue in patients with rheumatoid arthritis after a 6-month course of TNF inhibitors: prospective intervention study 
and partial economic evaluation. Scand J Rheumatol 38(4):246250. https://doi.org/10.1080/03009740902748264

4. Wcisło-Dziadecka D, Zbiciak-Nylec M, Brzezińska-Wcisło L, Mazurek U (2016) TNF- $\alpha$ in a molecularly targeted therapy of psoriasis and psoriatic arthritis. Postgrad Med J 92(1085):172178. https://doi.org/10.1136/postgradmedj-2015-133419

5. Barton JL (2009) Patient preferences and satisfaction in the treatment of rheumatoid arthritis with biologic therapy. Patient Prefer Adherence 3:335-344

6. Thurstone LL (1927) A law of comparative judgment. Psychol Rev 34(4):273-286. https://doi.org/10.1037/h0070288

7. Lancaster KJ (1966) A new approach to consumer theory. J Polit Econ 74(2): 132-157

8. McFadden D (1974) Conditional logit analysis of qualitative choice behaviour. In: Zarembka P (ed) Frontiers of econometrics. Academic Press, New York, pp 105-142

9. Alten R, Kruger K, Rellecke J, Schiffner-Rohe J, Behmer O, Schiffhorst G, Nolting HD (2016) Examining patient preferences in the treatment of rheumatoid arthritis using a discrete-choice approach. Patient Prefer Adherence 10:2217-2228. https://doi.org/10. 2147/PPA.S117774

10. Augustovski F, Beratarrechea A, Irazola V, Rubinstein F, Tesolin P, Gonzalez J, Lencina V, Scolnik M, Waimann C, Navarta D, Citera G, Soriano ER (2013) Patient preferences for biologic agents in rheumatoid arthritis: a discrete-choice experiment. Value Health 16(2):385-393. https://doi.org/10.1016/j.jval.2012.11.007

11. Hazlewood GS, Bombardier C, Tomlinson G, Thorne C, Bykerk VP, Thompson A, Tin D, Marshall DA (2016) Treatment preferences of patients with early rheumatoid arthritis: a discrete-choice experiment. Rheumatology (Oxford) 55(11):1959-1968. https:// doi.org/10.1093/rheumatology/kew280

12. Fraenkel L (2004) Patient preferences for treatment of rheumatoid arthritis. Ann Rheum Dis 63(11):1372-1378. https://doi.org/10. 1136/ard.2003.019422

13. Fifer S, Rose J, Hamrosi KK, Swain D (2018) Valuing injection frequency and other attributes of type 2 diabetes treatments in
Australia: a discrete choice experiment. BMC Health Serv Res 18(1):675. https://doi.org/10.1186/s12913-018-3484-0

14. Zhou M, Thayer WM, Bridges JFP (2018) Using latent class analysis to model preference heterogeneity in health: a systematic review. Pharmacoeconomics 36(2):175-187. https://doi.org/10.1007/ s40273-017-0575-4

15. Scalone L, Sarzi-Puttini P, Sinigaglia L, Montecucco C, Giacomelli R, Lapadula G, Olivieri I, Giardino AM, Cortesi PA, Mantovani LG, Mecchia M (2018) Patients', physicians', nurses', and pharmacists' preferences on the characteristics of biologic agents used in the treatment of rheumatic diseases. Patient Prefer Adherence 12: 2153-2168. https://doi.org/10.2147/PPA.S168458

16. Hensher DA, Rose JM, Greene WH (2015) Applied choice analysis. A Primer. 2nd. edn. Cambridge University Press, Cambridge

17. Harrison M, Marra C, Shojania K, Bansback N (2015) Societal preferences for rheumatoid arthritis treatments: evidence from a discrete choice experiment. Rheumatology (Oxford) 54(10):18161825. https://doi.org/10.1093/rheumatology/kev113

18. Coast J, Al-Janabi H, Sutton EJ, Horrocks SA, Vosper AJ, Swancutt DR, Flynn TN (2012) Using qualitative methods for attribute development for discrete choice experiments: issues and recommendations. Health Econ 21(6):730-741. https://doi.org/10.1002/hec. 1739

19. Rose JM, Bliemer MCJ (2009) Constructing efficient stated choice experimental designs. Transp Rev 29(5):587-617. https://doi.org/ $10.1080 / 01441640902827623$

20. Heiberg T, Kvien TK (2002) Preferences for improved health examined in 1,024 patients with rheumatoid arthritis: pain has highest priority. Arthritis Rheum 47(4):391-397. https://doi.org/10.1002/ art.10515

Publisher's note Springer Nature remains neutral with regard to jurisdictional claims in published maps and institutional affiliations. 